\title{
A promising therapeutic strategy for metastatic gestational trophoblastic disease: Engineered anticancer gene-expressing stem cells to selectively target choriocarcinoma (Review)
}

\author{
GYU-SIK KIM, KYUNG-A HWANG and KYUNG-CHUL CHOI \\ Laboratory of Biochemistry and Immunology, College of Veterinary Medicine, Chungbuk
National University, Cheongju, North Chungcheong 28644, Republic of Korea
}

Received March 15, 2018; Accepted September 19, 2018

DOI: $10.3892 / \mathrm{ol} .2019 .9911$

\begin{abstract}
Gestational trophoblastic disease (GTD) is an unusual disease occurring in pregnancy that originates from abnormal trophoblastic cells and comprises a group of diseases with different properties of invasion, metastasis and recurrence. The GTD group includes hydatidiform moles and gestational trophoblastic neoplasms (GTNs), with GTNs being divided into invasive moles, choriocarcinoma, placental site trophoblastic tumors and epithelioid trophoblastic tumors. The present review focuses on current effective treatments for GTD, including conventional and novel promising direct enzyme prodrug therapies (DEPTs). Conventional therapies, such as chemotherapy and hysterectomy, are currently used in a clinical setting; however, the use of diverse DEPTs, including antibody-DEPT and gene-DEPT is also being attempted to cure GTNs. In addition, gene delivery tools using genetically engineered neural stem cells (NSCs) are presently being examined for the treatment of GTNs. The tumor-tropism of NSCs by chemoattractant factors is a unique characteristic of these cells and can serve as a vehicle to deliver anticancer agents. Previous studies have demonstrated that injection with NSC-expressing suicide genes into xenograft animal models has a significant inhibitory effect on tumor growth. Stem cells can be genetically engineered to express anticancer genes, which migrate to the metastatic sites and selectively target cancer cells, and are considered to effectively target metastatic GTNs. However, the safety issue of stem cell therapy, such as tumorigenesis, remains a challenge. Novel therapies comprising a combination of conventional and novel promising treatments
\end{abstract}

Correspondence to: Professor Kyung-Chul Choi, Laboratory of Biochemistry and Immunology, College of Veterinary Medicine, Chungbuk National University, E12-1, Chungdae-ro 1, Seowon-gu, Cheongju, North Chungcheong 28644, Republic of Korea

E-mail:kchoi@cbu.ac.kr

Key words: therapeutic stem cell, gestational trophoblastic disease, choriocarcinoma, metastatic cancer, direct enzyme prodrug therapy are anticipated to be definitive treatments for metastasized and/or recurrent patients with GTNs.

\section{Contents}

1. Introduction

2. Types of GTD

3. Current therapeutic methods and research for GTD

4. Gene therapy using genetically engineered neural stem cells (NSCs)

5. Conclusions

\section{Introduction}

Gestational trophoblastic diseases (GTDs) are a group of disorders caused by the abnormal growth of trophoblast cells derived from placenta-forming tissues during pregnancy $(1,2)$. GTDs can usually be diagnosed by ultrasound scans and blood tests during pregnancy (3). Malignant GTDs are diagnosed by an elevated level of $\beta$-human chorionic gonadotropin (hCG) $(1,4)$. According to data from a study by the French Trophoblastic Disease Reference Center, $30 \%$ of patients were initially diagnosed as having ectopic pregnancies, and 7 out of 18 patients initially received a misdiagnosis (5).

GTD is a term that includes benign and malignant tumors in this tissue. Hydatidiform moles are included in the benign GTD group upon clinicopathological classification. There are four types of malignant GTD; invasive moles, choriocarcinoma, placental site trophoblastic tumors and epithelioid trophoblastic tumors $(6,7)$. Hydatidiform moles can occasionally progress to invasive moles or choriocarcinoma and spread rapidly. Choriocarcinoma, a malignant GTD, is a highly invasive tumor that is more likely to spread to other organs, including the lungs, liver and brain, through hematogenous routes $(8,9)$. A previous study reported that the incidence of choriocarcinoma in pregnant women was approximately three to nine times higher in Asia than in Europe and North America $(10,11)$. Compared with the hydatidiform mole, which accounts for $80 \%$ of all GTD cases, choriocarcinoma is relatively rare, and placental site 
trophoblastic tumors and epithelioid trophoblastic tumors are even less well known, and have been the subject of fewer studies $(10,12)$.

According to the International Federation of Gynecology and Obstetrics (FIGO), the majority of cases of choriocarcinoma are chemotherapy-sensitive, with a survival rate of nearly $100 \%$ in low-risk groups and $>80 \%$ in high-risk groups (13-15). There are four stages in FIGO staging system: stage 1 (only in the uterus), stage 2 (expansion into genital structures), stage 3 (extension of disease into lungs) and stage 4 (extension to the metastatic sites of the whole body) (15). Despite the fact that chemotherapy results in a significant cure rate, when cancer cells widely metastasize, the cure rate remains poor (16). Therefore, the development of effective therapies is the focus of present studies. In the present review, the characteristics of each type of GTD are presented, as well as the current strategies for GTD treatment, focusing on novel promising stem cell therapies.

\section{Types of GTD}

Hydatidiform mole. A hydatidiform mole is a disease caused by the atypical growth of normal trophoblastic cells, and is the most common benign lesion of the GTDs. The moles are classified into two types, complete hydatidiform moles and partial hydatidiform moles, according to morphological, histopathological and cytogenetic analysis (11). The treatment of the majority of patients afflicted with the two types of hydatidiform mole is focused on removal by dilation and curettage $(17,18)$. There are two main risk factors for developing the moles: i) Maternal age; women $\leq 16$ years or $>40$ years of age are 5 to 10 times more likely to develop hydatidiform moles than women aged 16-40 years; and ii) a previous history of a hydatidiform mole, which increases the incidence of another developing by $\sim 1.8 \%$ (19).

Invasive moles. An invasive mole is a neoplasia that grows in the uterine wall; it can spread to other areas of the body, including the vagina, vulva and lungs, and usually occurs following conception in women of reproductive age $(20,21)$. The most common signs of an invasive mole are prolonged vaginal bleeding and uterine enlargement. Invasive moles are clinically diagnosed by changes in $\mathrm{hCG}$ levels and are generally curable by extirpative procedures or hysterectomy (22).

Choriocarcinoma. Choriocarcinoma is a trophoblastic cancer that is liable to spread to multiple organs through hematogenous pathways. The most common symptom is vaginal bleeding, which also occurs in women with hydatidiform moles or during abnormal pregnancy (23). Choriocarcinoma is a rare cancer; however, the incidence of choriocarcinoma in Asian women is $\sim 3$ to 9 times higher than that in women in Europe and North America (9,24). Due to the high potential of vascular invasion, there are high risks of early metastasis to other organs, including the lungs, vagina, brain and liver $(13,25)$. The majority of choriocarcinomas are treated with single-agent or combination chemotherapy depending on the severity, and the chemotherapy has been shown to exhibit a significant therapeutic effect (26). However, drug resistance and systemic metastasis decrease the cure rate of chemotherapy (26).

Placental site trophoblastic tumors. A placental site trophoblastic tumor is a monophasic neoplasm GTD originating from extravillous trophoblasts $(27,28)$; it is a benign lesion that develops from the placental implantation site and accounts for $0.25-5 \%$ of GTD cases globally (29). However, $10-15 \%$ of cases of this disease were reported to be clinically malignant tumors (30). Placental site trophoblastic tumors are a unique manifestation compared with other types of GTD, and this is due to several features: i) relatively low hCG serum levels; ii) late-onset metastasis; iii) slower growth; and iv) less sensitivity to chemotherapy (29). As the placental site trophoblastic tumor is generally resistant to chemotherapy, hysterectomy has been reported as an appropriate treatment (31).

Epithelioid trophoblastic tumors. An epithelioid trophoblastic tumor is a rare form of GTD.In 1998, it was identified as a distinct entity (32). It has been reported that this tumor commonly develops in fertile women with a history of gestational events, including molar pregnancy and spontaneous abortion, and that latency is between 2 months and 25 years (33). The incidence rate for the tumor is $<2 \%$ among all GTDs (34). An epithelioid trophoblastic tumor is clinically similar to a placental site trophoblastic tumor as, it is resistant to chemotherapy and is slow growing (35). For patients with non-metastatic epithelioid trophoblastic tumors, a hysterectomy is recommended to maximize the therapeutic opportunity (34).

\section{Current therapeutic methods and research for GTD}

Malignant GTDs in the gestational trophoblastic neoplasm (GTN) classification include invasive moles, choriocarcinoma, placental site trophoblastic tumors and epithelioid trophoblastic tumors (26). Treatment of invasive moles and choriocarcinoma is principally associated with chemotherapy (36). The FIGO anatomical staging system is used to appraise the prognosis of patients and predict appropriate therapeutic strategies (15). Lung metastasis occurs in $\sim 70 \%$ of patients with GTN, and brain metastasis occurs in 8-15\% (37). The brain metastasis of a GTN is characterized by central necrosis and hemorrhage. Therefore, these patients are likely to present with neurological deterioration and intracerebral hemorrhage (ICH) (38). The probability of a cure rests on several prognostic factors, including age, pregnancy status, $\beta$-hCG concentration, extent of metastasis and tumor size (10).

Current treatments for GTD. One of the most effective remedies for hydatidiform moles is the termination of pregnancy (39-41). The termination of pregnancy diminishes the symptoms and prevents subsequent complications (42). Another possible treatment is chemotherapy. Methotrexate and dactinomycin are major chemotherapeutic drugs used in GTD (43). Hydatidiform moles have been successfully treated with methotrexate (44). In addition, the main treatment for invasive moles and choriocarcinoma is chemotherapy (36). The appropriate treatment for patients in the low-risk disease group is single-agent chemotherapy (36). The majority of patients with choriocarcinoma ( $95 \%)$ caused by molar pregnancy 
belong to this group, and treatment with methotrexate and dactinomycin alleviated the entire choriocarcinoma in 50-90\% of patients $(10,45)$. Of the total molar pregnancies, $80-85 \%$ of cases are benign without local relapse or metastasis to other organs. A total of $15-20 \%$ are invasive, and $<5 \%$ are malignant with metastatic lesions (45). In the case of the high-risk disease group, combination chemotherapy is required instead of single-agent chemotherapy (46). A previous study showed that patients with recurrent malignant trophoblastic diseases also had a favorable prognosis with multiple-agent therapy, and 5-year survival rates were significantly increased (47).

Chemotherapy is regarded as the primary treatment for patients with GTN. However, patients with chemo-resistant or recurrent tumors require surgical therapy. Prior to performing resection, medical imaging tests are attempted in order to confirm the presence of lesions in the primary site or other organs. The majority of these tests are combined with chemotherapy to minimize metastatic potential by tissue manipulation during the treatment period. Furthermore, this combination therapy has the advantage of reducing the length of the hospitalization period and the number of chemotherapy cycles (37).

Treatment of GTD with direct enzyme prodrug therapy $(D E P T)$. DEPT is defined as a therapy that converts pro-drugs to drugs at the desired location using artificially introduced enzymes $(48,49)$. DEPT has the advantage of reducing the systemic toxicity of drugs by gaining active drugs only at a specific location (50). Due to this feature, a number of studies have been conducted to demonstrate the therapeutic effect of DEPT on choriocarcinoma.

Among the various types of DEPT, antibody-DEPT (ADEPT) exhibited antitumor effects in choriocarcinoma animal xenograft models (51). In ADEPT, antibodies designed against cancer antigens are connected to enzymes, and antibody-connected enzymes can selectively bind to cancer cells. Effective ADEPT should be able to produce long-term cytotoxicity in tumors linked with antibodies without serious toxicity to normal tissues (52). In a previous study using ADEPT, bacterial enzyme carboxypeptidase G2 exhibited a significant reduction of tumor growth resistance to conventional chemotherapy in a human choriocarcinoma xenograft model (51).

Gene-DEPT (GDEPT) is a method of selectively delivering genes that convert cytotoxic-prodrugs to drugs in tumor sites (53). The genes are selectively expressed in cancer cells by tumor-specific promoters or viral transfection. Weyel et al (54) confirmed that tumor growth in the choriocarcinoma xenograft model was inhibited by GDEPT using $\beta$-glucuronidase, which converts HMR 1826 to doxorubicin. GDEPT can be used to selectively target human malignancies, including GTNs, while reducing the adverse effects of biological drugs.

\section{Gene therapy using genetically engineered neural stem cells (NSCs)}

NSCs as a gene delivery tool for cancer treatment. NSCs are progenitor cells of the central nervous system (CNS) and are defined as self-renewing, multipotent cells that differentiate into neurons, astrocytes and oligodendrocytes (55). It has been assumed that it would be feasible to develop alternative therapies for neurological diseases using the multipotential characteristics of NSCs (56). According to data from a studies published since 2000, NSCs were detected near the metastatic tumor when the stem cells were transplanted into a site remote from the brain neoplasia in animal models and found to be effective in delivering diverse therapeutic genes such as suicide genes and immunomodulatory genes to tumor foci (57-59). NSCs have several unique features: i) prolonged cell proliferation; ii) integration into the brain of the host without changing normal functions; and iii) migration toward neoplasms $(60,61)$. Therefore, it is possible to target cancer cells by producing NSCs with chemotherapeutic properties $(57,61)$.

Tumor-tropism of NSCs is indicated by chemoattractant factors produced in glioblastoma multiform or normal tissue injured by tumor growth (62). To investigate this ability of the NSCs, the majority of studies were initially performed using intracranial glioma animal models, and their migration ability to various cancer types, including breast cancer, melanoma brain metastases, pancreatic cancer, neuroblastoma and lung cancer, was further confirmed $(63,64)$. In a 2008 study, a correlation was identified between hypoxia and NSC migration ability (62). In glioma xenograft models, NSCs were distributed in hypoxic regions of intracranial tumors, and the expression of chemoattractant factors, including stromal cell-derived factor-1, vascular endothelial growth factor (VEGF) and urokinase-type plasminogen activator, were relatively decreased in hypoxia-inducible factor- $1 \alpha$-knockdown cells (62). In addition, a variety of factors, including stem cell factor/c-kit system, VEGF/VEGF receptor, high mobility group box $1 /$ receptor for advanced glycation end products, hepatocyte growth factor/c-met signaling, Annexin II and monocyte chemoattractant protein 1 , were identified, which were associated with tumor-tropism of NSCs toward tumors (65). Based on the inherent migration ability of NSCs, stem cell therapy expressing anticancer genes has emerged as a promising therapy for metastatic cancer, including GTNs.

GDEPT and immunomodulatory gene therapy using NSCs. GDEPT using NSCs, a method that uses genetically engineered NSCs to express a gene encoding an enzyme that converts a non-cytotoxic or low cytotoxic prodrug to a cytotoxic metabolite, is a major approach for cancer therapy (66). These genetically engineered NSCs confer the following advantages on an effective cancer treatment: i) cancer-specific migration; ii) minimization of the risk of adverse drug events; and iii) increased treatment efficiency (61). Since NSCs have the capability for cancer selective migration, genetically engineered NSCs can deliver the anticancer genes at the tumor sites. Furthermore, Joo et al (67) reported that tumors were suppressed in the left and right hemispheres of the brain when genetically engineered NSCs were injected into the left hemisphere in brain metastasis animal models. This suggests that NSCs can migrate to the tumor-forming sites anywhere in the body and inhibit tumor growth. Cancer treatment using foreign enzymes expressed at the tumor site is an essential feature of GDEPT and can minimize the side effects when compared with conventional chemotherapy (57). The anticancer genes of GDEPT for humans typically use 
Table I. Current and potential therapeutic methods for gestational trophoblastic disease.

Treatments Cancer type

(Refs.)

Conventional therapy

Surgical therapy

Resection

GTN

Chemotherapy

Methotrexate and/or dactinomycin

GTN

Methotrexate and EMA/CO ${ }^{a}$

Hydatidiform mole

DEPT

\section{ADEPT}

Carboxypeptidase G2

Choriocarcinoma

GDEPT

$\beta$-glucuronidase

Choriocarcinoma

NSC therapy

Carboxyl esterase

Lung cancer

$\mathrm{CD}$ and/or IFN- $\beta$

Breast cancer and choriocarcinoma

$\mathrm{CD}$ and HSV-1 thymidine kinase

Ovarian carcinoma

Interleukin 12

Glioma

Interleukin 23

Glioma

${ }^{a}$ Multi-agent chemotherapy, including etoposide, methotrexate, actinomycin D, cyclophosphamide and vincristine. GTN, gestational trophoblastic neoplasm; DEPT, direct enzyme prodrug therapies; ADEPT, antibody-DEPT; GDEPT, gene-DEPT; NSC, neural stem cell; IFN- $\beta$, interferon- $\beta$; CD, cytosine deaminase; HSV-1, Herpes Simplex Virus type 1.

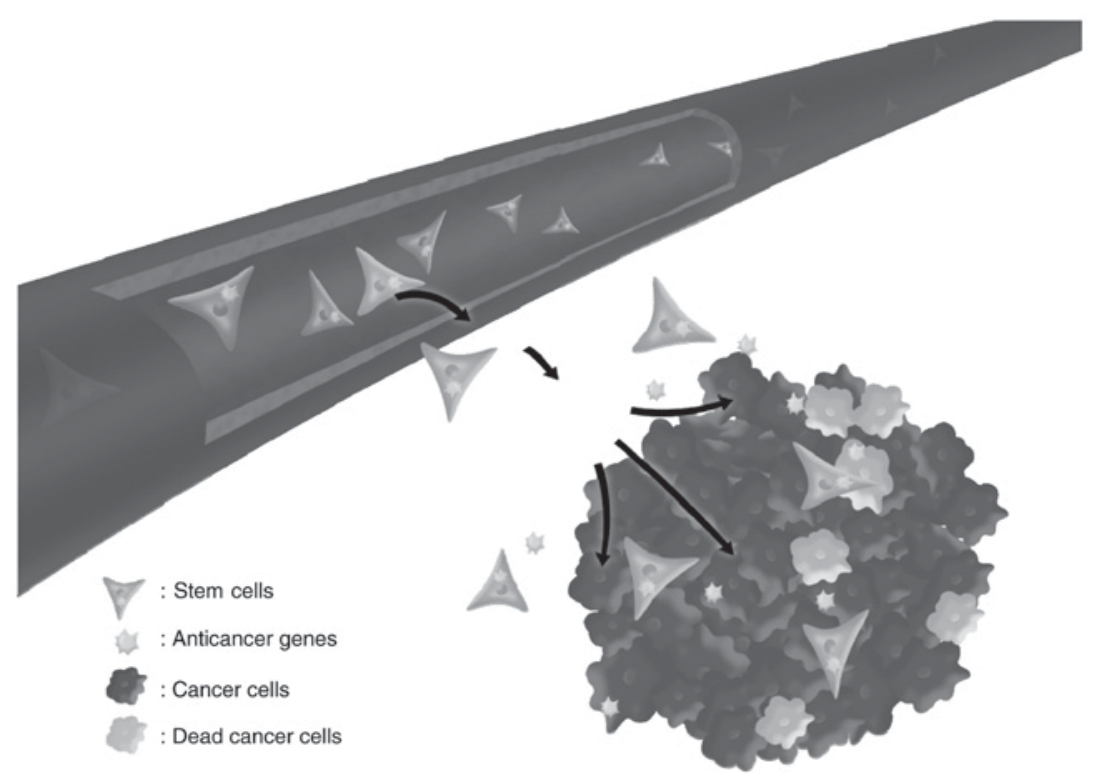

Figure 1. Schematic diagram illustrating how stem cells target disseminated tumors. Genetically engineered neural stem cells express anticancer genes targeted to tumors spread throughout the whole body, specifically inhibiting the cancer cells at the tumor site.

those originated from other species in order to minimize the pro-drug activity of endogenous enzymes (68). One example of stem cells expressing such genes is HB1.F3.CD cells, which are genetically engineered NSCs expressing the Escherichia coli (E. coli) cytosine deaminase (CD) gene. HB1.F3.CD cells were genetically engineered from fetal telencephalon-derived
HB1.F3 cells (69). The CD gene originating in E. coli converts non-cytotoxic agent 5-fluorocytosine (5-FC) to cytotoxic agent 5-fluorouracil (5-FU) (70). E. coli CD is an enzyme from the pyrimidine salvage pathway that deaminates the anti-fungal drug to 5-FU (71). Compared with direct 5-FU chemotherapy, the $\mathrm{CD} / 5-\mathrm{FC}$ approach may be clinically beneficial due to the 
unique property of 5-FC, in that it can cross the blood brain barrier $(72,73)$. Numerous studies demonstrated that HB1. F3.CD cells expressing the CD gene significantly inhibited the proliferation of cancer cells and suppressed tumor growth in the presence of 5-FC $(63,69,74-76)$.

Treatment of sickness by enhancing or diminishing the immune response is termed immunotherapy. The use of cytokine genes to increase the antitumor response is particularly effective in cancer treatment. A previous study by Panelli and Marincola identified that $9 \%$ of renal cell carcinoma and $7 \%$ of melanoma patients were cured when treated with high concentrations of interleukin (IL)-2 in a total of 283 patients (77). Thus, NSCs engineered to express immunomodulatory genes, including interferon (IFN)- $\beta$, IL-4, IL-12 and IL-23, can effectively treat cancer by expressing them at the tumor site (57). For example, in mouse xenograft models with human colorectal cancer, tumors of mice injected with NSCs expressing CD alone (HB1.F3.CD) exhibited a 56\% reduction of tumor volume compared with the control, while those of mice injected with NSCs expressing CD and IFN- $\beta$ (HB1.F3.CD.IFN- $\beta$ ) exhibited a reduction of $\sim 76 \%(75)$. Furthermore, treatment with these stem cells in choriocarcinoma metastasis or xenograft models inhibited tumor growth and decreased metastasis (78). Kim et al (78) reported that the volume of the choriocarcinoma tumor was smaller by approximately half compared with that of the control groups when using therapeutic genes in a choriocarcinoma xenograft model, and that the lung metastatic area of the HB1.F3.CD. IFN- $\beta$ group was reduced by $\sim 45 \%$ compared with that of the HB1.F3 group in a metastasis model.

However, stem cell-based gene therapy has two major challenges to overcome. The first challenge is the safety of the therapy. When human stem cells remain stable in the body, the cells can cause genetic and epigenetic alterations (79). Furthermore, undifferentiated embryonic stem cells are likely to form teratocarcinoma (79). The second challenge is the immune response. The vector that introduces the gene has the potential to induce an immune response, and non-autologous stem cells will result in immunological rejection (79). These issues are obstacles preventing phase III clinical trials of stem cell-based gene therapy from being conducted, and further studies should be performed in order to address them.

Overall, NSC therapy is a promising strategy as it is suitable as a tool for delivering anticancer genes to the metastatic sites of the body and it has been proven to have significant therapeutic effects. However, additional research is essential for the development of a stable and effective therapeutic method.

\section{Conclusions}

In the present review, conventional therapeutic tools and novel research fields for treating GTD were investigated and these are summarized in Table I. Chemotherapy, a major treatment for GTNs, has already achieved a significant cure rate. Depending on the extent of metastasis determined by FIGO stage, chemotherapy with a single or multiple agents is used; however, there is a possibility of systemic toxicity and recurrence. Furthermore, chemotherapy has limited effects on recurrent tumors due to their chemical resistance. It is imperative to overcome these problems in order to effectively treat the tumors at the metastatic site.

Previous studies have demonstrated that NSCs have the ability to migrate to the metastatic regions of the whole body, as demonstrated by studies in which NSC injected in the left hemisphere suppressed tumors in the right hemisphere. The intrinsic properties of these cells are expected to be clinically useful for the targeted delivery of therapeutic agents to tumors that have spread throughout the body. However, the number of NSCs that can reach tumor nodules located at a considerable distance from the injected site will likely be limited. Therefore, studies of NSC-based therapy should maintain or improve the intrinsic tumor tropisms of NSCs.

As a result of the cancer-specific migration effect, NSCs are better suited as a therapeutic delivery tool for metastatic tumors than other cell types. The CD/5-FC approach with NSCs has a tremendous advantage in the field of drug delivery for cancer treatment. Furthermore, NSCs expressing several therapeutic genes, e.g. CD-expressing NSCs in combination with IFN- $\beta$, exhibited synergism of tumor suppression. Thus, genetically engineered stem cells expressing anticancer genes migrate to the metastatic sites and selectively target cancer cells (Fig. 1). Although chemotherapy for GTNs has considerable cure rates, combination with novel therapies is required to ensure definitive treatment of patients with metastasis and recurrence.

\section{Acknowledgements}

Not applicable.

\section{Funding}

This study was supported by the Basic Science Research Program through the National Research Foundation of Korea funded by the Ministry of Education, Science and Technology (grant no. 2016R1D1A1A09919809), and by the Global Research and Development Center Program through the National Research Foundation of Korea funded by the Ministry of Science and ICT (grant no. 2017K1A4A3014959).

\section{Availability of data and materials}

Not applicable.

\section{Authors' contributions}

GSK and KCC were involved in the study conception and design. GSK collected and assembled data; prepared the figure and table. GSK and KAH wrote the manuscript, and $\mathrm{KCC}$ reviewed literature. GSK and $\mathrm{KAH}$ ensured that questions related to the accuracy or integrity of the work are appropriately investigated and resolved. GSK, KAH and KCC agreed to be accountable for all aspects of the work, and KCC provided final approval of the manuscript to be published.

\section{Ethics approval and consent to participate}

Not applicable. 


\section{Patient consent for publication}

Not applicable.

\section{Competing interests}

The authors declare that they have no competing interests.

\section{References}

1. Sun P, Wu Q, Ruan G, Zheng X, Song Y, Zhun J, Wu L and Gotlieb WH: Expression patterns of maspin and mutant p53 are associated with the development of gestational trophoblastic neoplasia. Oncol Lett 12: 3135-3142, 2016.

2. Savage P, Williams J, Wong SL, Short D, Casalboni S, Catalano K and Seckl M: The demographics of molar pregnancies in England and Wales from 2000-2009. J Reprod Med 55: 341-345, 2010

3. Begum SA, Bhuiyan ZR, Akther R, Afroz R, Chowdhury A and Keya KA: A review on gestational trophoblastic disease. Bangladesh Med J 44, 2015.

4. Gestational Trophoblastic Disease Treatment $\left(\mathrm{PDQ}^{\circledR}\right)$. Health Professional Version. In: PDQ Cancer Information Summaries [Internet]. National Cancer Institute (US), Bethesda, MD, 2002.

5. Horowitz NS, Goldstein DP and Berkowitz RS: Placental site trophoblastic tumors and epithelioid trophoblastic tumors: Biology, natural history, and treatment modalities. Gynecol Oncol 144: 208-214, 2017.

6. Lee YJ, Park JY, Kim DY, Suh DS, Kim JH, Kim YM, Kim YT and Nam JH: Comparing and evaluating the efficacy of methotrexate and actinomycin D as first-line single chemotherapy agents in low risk gestational trophoblastic disease. J Gynecol Oncol 28: e8, 2017.

7. May T, Goldstein DP and Berkowitz RS: Current chemotherapeutic management of patients with gestational trophoblastic neoplasia. Chemother Res Pract 2011: 806256, 2011.

8. Guo J, Zhong C, Liu Q, Xu J, Zheng Y, Xu S, Gao Y, Guo Y, Wang Y, Luo Q, et al: Intracranial choriocarcinoma occurrence in males: Two cases and a review of the literature. Oncol Lett 6 : 1329-1332, 2013.

9. Tian Q, Xue Y, Zheng W, Sun R, Ji W, Wang X and An R: Overexpression of hypoxia-inducible factor $1 \alpha$ induces migration and invasion through Notch signaling. Int J Oncol 47: 728-738, 2015.

10. Seckl MJ, Sebire NJ and Berkowitz RS: Gestational trophoblastic disease. Lancet 376: 717-729, 2010.

11. Lurain JR: Gestational trophoblastic disease I: Epidemiology, pathology, clinical presentation and diagnosis of gestational trophoblastic disease, and management of hydatidiform mole. Am J Obstet Gynecol 203: 531-539, 2010.

12. Lima LL, Parente RC, Maestá I, Amim Junior J, de Rezende Filho JF, Montenegro CA and Braga A: Clinical and radiological correlations in patients with gestational trophoblastic disease. Radiol Bras 49: 241-250, 2016.

13. Soper JT: Gestational trophoblastic disease. Obstet Gynecol 108 176-187, 2006.

14. Ghaemmaghami F, Behtash N, Soleimani K and Hanjani P: Management of patients with metastatic gestational trophoblastic tumor. Gynecol Oncol 94: 187-190, 2004.

15. FIGO Committee on Gynecologic Oncology: Current FIGO staging for cancer of the vagina, fallopian tube, ovary, and gestational trophoblastic neoplasia. Int J Gynaecol Obstet 105: 3-4, 2009.

16. Chen Y, Qian H, Wang H, Zhang X, Fu M, Liang X, Ma Y, Zhan Q, Lin C and Xiang Y: Ad-PUMA sensitizes drug-resistant choriocarcinoma cells to chemotherapeutic agents. Gynecol Oncol 107: 505-512, 2007.

17. Suksai M, Suwanrath C, Kor-Anantakul O, Geater A, Hanprasertpong T, Atjimakul T and Pichatechaiyoot A: Complete hydatidiform mole with co-existing fetus: Predictors of live birth. Eur J Obstet Gynecol Reprod Biol 212: 1-8, 2017.

18. Schwentner L, Schmitt W, Bartusek G, Kreienberg R and Herr D: Cervical hydatidiform mole pregnancy after missed abortion presenting with severe vaginal bleeding: Case report and review of the literature. Eur J Obstet Gynecol Reprod Biol 156: 9-11, 2011.

19. Tse KY and Ngan HY: Gestational trophoblastic disease. Best Pract Res Clin Obstet Gynaecol 26: 357-370, 2012.
20. McDonald TW and Ruffolo EH: Modern management of gestational trophoblastic disease. Obstet Gynecol Surv 38: 67-83, 1983.

21. Ozalp SS, Telli E, Oge T, Tulunay G, Boran N, Turan T, Yenen M, Kurdoglu Z, Ozler A, Yuce K, et al: Multicenter analysis of gestational trophoblastic neoplasia in Turkey. Asian Pac J Cancer Prev 15: 3625-3628, 2014.

22. Akyol A, Şimşek M and Üçer Ö: Giant invasive mole presenting as a cause of abdominopelvic mass in a perimenopausal woman: An unusual presentation of a rare pathology. Obstet Gynecol Sci 59: 548-553, 2016.

23. Garner EI, Goldstein DP, Feltmate CM and Berkowitz RS: Gestational trophoblastic disease. Clin Obstet Gynecol 50: 112-122, 2007.

24. Ibi T, Hirai K, Bessho R, Kawamoto M, Koizumi K and Shimizu K: Choriocarcinoma of the lung: Report of a case. Gen Thorac Cardiovasc Surg 60: 377-380, 2012.

25. Berkowitz RS and Goldstein DP: Current management of gestational trophoblastic diseases. Gynecol Oncol 112: 654-662, 2009.

26. Monchek R and Wiedaseck S: Gestational trophoblastic disease: An overview. J Midwifery Womens Health 57: 255-259, 2012.

27. Shih IM and Kurman RJ: The pathology of intermediate trophoblastic tumors and tumor-like lesions. Int J Gynecol Pathol 20: 31-47, 2001.

28. Scully RE and Young RH: Trophoblastic pseudotumor: A reappraisal. Am J Surg Pathol 5: 75-76, 1981.

29. Behnamfar F, Rouholamin S and Esteki M: Presentation of Placental Site Trophoblastic Tumor with Amenorrhea. Adv Biomed Res 6: 29, 2017.

30. Eckstein RP, Paradinas FJ and Bagshawe KD: Placental site trophoblastic tumour (trophoblastic pseudotumour): A study of four cases requiring hysterectomy including one fatal case. Histopathology 6: 211-226, 1982.

31. Newlands ES, Mulholland PJ, Holden L, Seckl MJ and Rustin GJ: Etoposide and cisplatin/etoposide, methotrexate, and actinomycin D (EMA) chemotherapy for patients with high-risk gestational trophoblastic tumors refractory to EMA/cyclophosphamide and vincristine chemotherapy and patients presenting with metastatic placental site trophoblastic tumors. J Clin Oncol 18: 854-859, 2000.

32. Park JW and Bae JW: Epithelioid Trophoblastic Tumor in a Postmenopausal Woman: A Case Report. J Menopausal Med 22: 50-53, 2016.

33. Rodríguez-Trujillo A, Martínez-Serrano MJ, Saco A and Torné A: Two cases of epithelioid trophoblastic tumors in postmenopausal women. Menopause 24: 1304-1308, 2017.

34. Davis MR, Howitt BE, Quade BJ, Crum CP, Horowitz NS, Goldstein DP and Berkowitz RS: Epithelioid trophoblastic tumor: A single institution case series at the New England Trophoblastic Disease Center. Gynecol Oncol 137: 456-461, 2015.

35. Kim JH, Lee SK, Hwang SH, Kim JS, Yoon G, Lee YY, Kim TJ, Choi CH, Kim BG, Bae DS, et al: Extrauterine epithelioid trophoblastic tumor in hysterectomized woman. Obstet Gynecol Sci 60: 124-128, 2017.

36. Abrão RA, de Andrade JM, Tiezzi DG, Marana HR, Candido dos Reis FJ and Clagnan WS: Treatment for low-risk gestational trophoblastic disease: Comparison of single-agent methotrexate, dactinomycin and combination regimens. Gynecol Oncol 108: 149-153, 2008.

37. Lima LLA, Padron L, Câmara R, Sun SY, Rezende J and Braga A: The role of surgery in the management of women with gestational trophoblastic disease. Rev Col Bras Cir 44: 94-101, 2017.

38. Eoh KJ, Chung YS, Yim GW, Nam EJ, Kim S, Kim SW and Kim YT: Role of surgical therapy in the management of gestational trophoblastic neoplasia. Obstet Gynecol Sci 58: 277-283, 2015.

39. Berkowitz RS and Goldstein DP: Clinical practice. Molar pregnancy. N Engl J Med 360: 1639-1645, 2009.

40. Hurteau JA: Gestational trophoblastic disease: Management of hydatidiform mole. Clin Obstet Gynecol 46: 557-569, 2003.

41. Gerulath AH, Ehlen TG, Bessette P, Jolicoeur L and Savoie R; Society of Obstetricians and Gynaecologists of CanadaGynaecologic Oncologists of Canada; Society of Canadian Colposcopists: Gestational trophoblastic disease. J Obstet Gynaecol Can 24: 434-446, 2002 (In English; French).

42. Sebire NJ and Seck1 MJ: Gestational trophoblastic disease: Current management of hydatidiform mole. BMJ 337: a1193, 2008. 
43. Kang WD, Choi HS and Kim SM: Weekly methotrexate $(50 \mathrm{mg} / \mathrm{m}(2))$ without dose escalation as a primary regimen for low-risk gestational trophoblastic neoplasia. Gynecol Oncol 117: 477-480, 2010

44. De Vos M, Leunen M, Fontaine C and De Sutter P: Successful Primary Treatment of a Hydatidiform Mole with Methotrexate and EMA/CO. Case Rep Med 2009: 454161, 2009.

45. Shanbhogue AK, Lalwani N and Menias CO: Gestational trophoblastic disease. Radiol Clin North Am 51: 1023-1034, 2013.

46. Wenzel L, Berkowitz RS, Newlands E, Hancock B, Goldstein DP, Seckl MJ, Habbal R, Bernstein M, Kluhsman B, Kulchak-Rahm A, et al: Quality of life after gestational trophoblastic disease. J Reprod Med 47: 387-394, 2002

47. Lurain JR: Gestational trophoblastic disease II: Classification and management of gestational trophoblastic neoplasia. Am J Obstet Gynecol 204: 11-18, 2011.

48. Karjoo Z, Chen X and Hatefi A: Progress and problems with the use of suicide genes for targeted cancer therapy. Adv Drug Deliv Rev 99 (Pt A): 113-128, 2016

49. Zawilska JB, Wojcieszak J and Olejniczak AB: Prodrugs: a challenge for the drug development. Pharmacol Rep 65: 1-14, 2013.

50. Schellmann N, Deckert PM, Bachran D, Fuchs H and Bachran C: Targeted enzyme prodrug therapies. Mini Rev Med Chem 10 887-904, 2010

51. Springer CJ, Bagshawe KD, Sharma SK, Searle F, Boden JA, Antoniw P, Burke PJ, Rogers GT, Sherwood RF and Melton RG: Ablation of human choriocarcinoma xenografts in nude mice by antibody-directed enzyme prodrug therapy (ADEPT) with three novel compounds. Eur J Cancer 27: 1361-1366, 1991.

52. Bagshawe KD, Springer CJ, Searle F, Antoniw P, Sharma SK Melton RG and Sherwood RF: A cytotoxic agent can be generated selectively at cancer sites. Br J Cancer 58: 700-703, 1988.

53. Zhang J, Kale V and Chen M: Gene-directed enzyme prodrug therapy. AAPS J 17: 102-110, 2015.

54. Weyel D, Sedlacek HH, Müller R and Brüsselbach S: Secreted human beta-glucuronidase: A novel tool for gene-directed enzyme prodrug therapy. Gene Ther 7: 224-231, 2000.

55. Alenzi FQ, Lotfy M, Tamimi WG and Wyse RK: Review: Stem cells and gene therapy. Lab Hematol 16: 53-73, 2010.

56. Müller FJ, Snyder EY and Loring JF: Gene therapy: Can neural stem cells deliver? Nat Rev Neurosci 7: 75-84, 2006.

57. Benedetti S, Pirola B, Pollo B, Magrassi L, Bruzzone MG, Rigamonti D, Galli R, Selleri S, Di Meco F, De Fraja C, et al: Gene therapy of experimental brain tumors using neural progenitor cells. Nat Med 6: 447-450, 2000.

58. Aboody KS, Brown A, Rainov NG, Bower KA, Liu S, Yang W, Small JE, Herrlinger U, Ourednik V, Black PM, et al: Neural stem cells display extensive tropism for pathology in adult brain: Evidence from intracranial gliomas. Proc Natl Acad Sci USA 97: 12846-12851, 2000.

59. Ahmed AU, Alexiades NG and Lesniak MS: The use of neural stem cells in cancer gene therapy: Predicting the path to the clinic. Curr Opin Mol Ther 12: 546-552, 2010.

60. Consiglio A, Gritti A, Dolcetta D, Follenzi A, Bordignon C, Gage FH, Vescovi AL and Naldini L: Robust in vivo gene transfer into adult mammalian neural stem cells by lentiviral vectors. Proc Natl Acad Sci USA 101: 14835-14840, 2004.

61. Heo JR, Kim NH, Cho J and Choi KC: Current treatments for advanced melanoma and introduction of a promising novel gene therapy for melanoma (Review). Oncol Rep 36: 1779-1786, 2016.

62. Zhao D, Najbauer J, Garcia E, Metz MZ, Gutova M, Glackin CA, Kim SU and Aboody KS: Neural stem cell tropism to glioma: Critical role of tumor hypoxia. Mol Cancer Res 6: 1819-1829, 2008

63. Yi BR, Hwang KA, Aboody KS, Jeung EB, Kim SU and Choi KC: Selective antitumor effect of neural stem cells expressing cytosine deaminase and interferon-beta against ductal breast cancer cells in cellular and xenograft models. Stem Cell Res (Amst) 12: 36-48, 2014

64. Yi BR, Kim SU and Choi KC: Co-treatment with therapeutic neural stem cells expressing carboxyl esterase and CPT-11 inhibit growth of primary and metastatic lung cancers in mice. Oncotarget 5: 12835-12848, 2014.
65. Magge SN, Malik SZ, Royo NC, Chen HI, Yu L, Snyder EY, O'Rourke DM and Watson DJ: Role of monocyte chemoattractant protein-1 (MCP-1/CCL2) in migration of neural progenitor cells toward glial tumors. J Neurosci Res 87: 1547-1555, 2009.

66. Bonini C, Bondanza A, Perna SK, Kaneko S, Traversari C, Ciceri $\mathrm{F}$ and Bordignon $\mathrm{C}$ : The suicide gene therapy challenge: how to improve a successful gene therapy approach. Mol Ther 15: 1248-1252, 2007.

67. Joo KM, Park IH, Shin JY, Jin J, Kang BG, Kim MH, Lee SJ, Jo MY, Kim SU and Nam DH: Human neural stem cells can target and deliver therapeutic genes to breast cancer brain metastases. Mol Ther 17: 570-575, 2009.

68. Green LK, Storey MA, Williams EM, Patterson AV, Smaill JB, Copp JN and Ackerley DF: The Flavin Reductase MsuE Is a Novel Nitroreductase that Can Efficiently Activate Two Promising Next-Generation Prodrugs for Gene-Directed Enzyme Prodrug Therapy. Cancers (Basel) 5: 985-997, 2013.

69. Park GT, Kim SU and Choi KC: Anti-proliferative Effect of Engineered Neural Stem Cells Expressing Cytosine Deaminase and Interferon-beta against Lymph Node-Derived Metastatic Colorectal Adenocarcinoma in Cellular and Xenograft Mouse Models. Cancer Res Treat 49: 79-91, 2017.

70. Xie Y, Gilbert JD, Kim JH and Freytag SO: Efficacy of adenovirus-mediated $\mathrm{CD} / 5-\mathrm{FC}$ and $\mathrm{HSV}-1$ thymidine kinase/ganciclovir suicide gene therapies concomitant with p53 gene therapy. Clin Cancer Res 5: 4224-4232, 1999.

71. Mahan SD, Ireton GC, Knoeber C, Stoddard BL and Black ME: Random mutagenesis and selection of Escherichia coli cytosine deaminase for cancer gene therapy. Protein Eng Des Sel 17: 625-633, 2004

72. Vermes A, Guchelaar HJ and Dankert J: Flucytosine: A review of its pharmacology, clinical indications, pharmacokinetics, toxicity and drug interactions. J Antimicrob Chemother 46: $171-179,2000$

73. Ardiani A, Johnson AJ, Ruan H, Sanchez-Bonilla M, Serve K and Black ME: Enzymes to die for: Exploiting nucleotide metabolizing enzymes for cancer gene therapy. Curr Gene Ther 12: 77-91, 2012.

74. Kim DJ, Yi BR, Lee HR, Kim SU and Choi KC: Pancreatic tumor mass in a xenograft mouse model is decreased by treatment with therapeutic stem cells following introduction of therapeutic genes. Oncol Rep 30: 1129-1136, 2013.

75. Yi BR, Park MA, Lee HR, Kang NH, Choi KJ, Kim SU and Choi KC: Suppression of the growth of human colorectal cancer cells by therapeutic stem cells expressing cytosine deaminase and interferon- $\beta$ via their tumor-tropic effect in cellular and xenograft mouse models. Mol Oncol 7: 543-554, 2013.

76. Yi BR, Kim SU and Choi KC: Additional effects of engineered stem cells expressing a therapeutic gene and interferon- $\beta$ in a xenograft mouse model of endometrial cancer. Int J Oncol 47 171-178, 2015.

77. Panelli MC and Marincola FM: Immunotherapy update: from interleukin-2 to antigen-specific therapy. In: ASCO educational book. Perry MC (ed). American Society of Clinical Oncology, pp467-473, 1998 .

78. Kim GS, Heo JR, Kim SU and Choi KC: Cancer-Specific Inhibitory Effects of Genetically Engineered Stem Cells Expressing Cytosine Deaminase and Interferon- $\beta$ Against Choriocarcinoma in Xenografted Metastatic Mouse Models. Transl Oncol 11: 74-85, 2018

79. Zwaka TP: Use of Genetically Modified Stem Cells in Experimental Gene Therapies. National Institutes of Health (US), Bethesda, MD, 2006

80. Ehtesham M, Kabos P, Kabosova A, Neuman T, Black KL and Yu JS: The use of interleukin 12-secreting neural stem cells for the treatment of intracranial glioma. Cancer Res 62: 5657-5663, 2002.

81. Yuan X, Hu J, Belladonna ML, Black KL and Yu JS: Interleukin-23-expressing bone marrow-derived neural stem-like cells exhibit antitumor activity against intracranial glioma. CancerRes 66: 2630-2638, 2006. 